\title{
Numerical Simulation of Regional Stress Field under Complex Geological Condition
}

\author{
Tongxu Wang ${ }^{1, a}$, Wenhai Zheng ${ }^{1,2, b}$ and Saijiang Liang ${ }^{1, c}$ \\ ${ }^{1}$ Shandong University of Science and Technology, 579 Qianwangang Road Economic \& Technical \\ Development Zone, Qingdao Shandong Province, China, 266510 \\ ${ }^{2}$ Institute of Mechanics, Chinese Academy of Sciences, No.15 Beisihuanxi Road, Beijing, China, \\ 100190 \\ awtx6383@163.com, 'bwh1208@163.com, csdkdlsj@163.com
}

Keywords: geostress field, numerical simulation, measured data, complex structure, surface fluctuation

\begin{abstract}
In this paper, the geostress field of a large area complicated in geological structures was inverted with the stress data of a few measured points by using FLAC ${ }^{3 \mathrm{D}}$ numerical stimulation and regression analysis. Two types of models were built. One type is a big model without geological structures, which considered the influence of layer thickness, lithology, stratigraphic dip and ground surface fluctuation first, and then corrected the simulation results according to the measured data, and finally got the geostress field without regional structures by regression analysis. The other type is small regional structure models, which paid attention to the influence of depth, fault type and fault throw, or fold type and fold amplitude, and gained the influence range and coefficients of each geological structure to the geostress field. At last, the results of two types were integrated together, and the large area geostress field under complex geological condition was got. According to this method in allusion to a specific example, the principal stress isoline and vector horizontal projection of coal seam roof including three faults and one fold were obtained, which could analyze the stress magnitude and direction. The method above can solve the problem of how to use the stress data of a few measured points to gain a wide range geostress field under complex geological condition, which could also promote the study of geostress field inversion and have certain engineering application value.
\end{abstract}

\section{Introduction}

Initial stress field is the main factor that affects the stability of underground engineering, and master the stress distribution law is the basic to do the design, construction and supporting of an underground engineering [1-3]. Because of various factors, geostress can't be measured in a large quantities, and the results are also discrete to a certain degree [3]. So many scholars do the research on how to use little measured data to obtain a wide range regional stress field under complex geological condition. One of the feasible ways is to do corresponding numerical simulation [4-5].

But to a large area, there are so many geological structures in it and the lithology changes a lot, it's hard to do the numerical simulation or even build the model. As a result, this paper took simulation respectively and integration together as the research thoughts. In a big model without geological structures, it considered the influence of layer thickness, lithology, stratigraphic dip and surface fluctuation, and then corrected the simulation results according to measured data, and got the geostress field without regional structures by regression analysis finally. In small regional structure models, it paid attention to the influence of depth, fault type and fault throw, or fold type and fold amplitude, and gained the influence range and coefficients of each geological structure to the geostress field. At last, it integrated the results together, got the regional stress field under complex geological condition. This method is fit for stress field inversion under complex geological condition, especially the condition of deep mine. 


\section{Modeling}

The depth of 3401 working face in a coal mine is $640 \mathrm{~m}$. According to the 3 rd coal seam contour map, there exist three faults and one fold, which is normal fault F1, thrust fault F2, normal fault F3 and fold $\mathrm{Z} 1$ respectively. There are four measured geostress points, and the measured data is shown in table 1.

Table 1 Data of measured points/MPa

\begin{tabular}{cccccccc}
\hline No. of Points & Coordinates & S-XX & S-YY & S-ZZ & S-XY & S-XZ & S-YZ \\
\hline D1 & $(204,390,45)$ & -2.04 & -1.98 & -8.35 & -0.0002 & 0.0003 & -0.0080 \\
D2 & $(399,210,10)$ & -2.54 & -2.34 & -9.25 & 0.0000 & 0.0002 & -0.0085 \\
D3 & $(399,610,289)$ & -1.69 & -1.75 & -5.02 & -0.0001 & -0.0008 & -0.0275 \\
D4 & $(596,410,396)$ & -0.87 & -0.92 & -2.86 & 0.0000 & -0.0143 & -0.0300 \\
\hline
\end{tabular}

Each model is built according to the research thoughts above. The size of big model is 800 $\mathrm{m}($ length $) \times 800 \mathrm{~m}$ (width) $\times 675 \mathrm{~m}$ (height), which contains the rock seam from No. 1 to No. 11 shown in table 2 and the upper boundary reflects irregular topography. The size of small models is 200 $\mathrm{m}($ length $) \times 5 \mathrm{~m}$ (width) $\times 42 \mathrm{~m}$ (height), which contain the rock seam from No. 4 to No. 11 shown in table 2 and define as Mohr-Coulomb material. The models are shown in figure 1.

Table 2 Mechanical parameters of models

\begin{tabular}{ccccccc}
\hline $\begin{array}{c}\text { No. of } \\
\text { Seams }\end{array}$ & $\begin{array}{c}\text { Rock } \\
\text { Name }\end{array}$ & $\begin{array}{c}\text { Elastic } \\
\text { Modulus/Pa }\end{array}$ & $\begin{array}{c}\text { Poisson's } \\
\text { Ratio }\end{array}$ & $\begin{array}{c}\text { Tensile } \\
\text { strength/Pa }\end{array}$ & $\begin{array}{c}\text { Density } / \mathrm{kg} \cdot \mathrm{m}^{-3} \\
\text { Thickness } \\
/ \mathrm{m}\end{array}$ \\
\hline 1 & soil & $8 \mathrm{e} 9$ & 0.38 & $3.0 \mathrm{e} 6$ & 1200 & 225 \\
2 & sediment & $12 \mathrm{e} 9$ & 0.30 & $3.5 \mathrm{e} 6$ & 1500 & 220 \\
3 & gravel & $20 \mathrm{e} 9$ & 0.23 & $8.0 \mathrm{e} 6$ & 2000 & 190 \\
4 & aleurolite & $20 \mathrm{e} 9$ & 0.22 & $6.0 \mathrm{e} 6$ & 2000 & 11 \\
5 & 2nd coal & $4 \mathrm{e} 9$ & 0.38 & $2.0 \mathrm{e} 6$ & 1400 & 1 \\
6 & sandstone & $15 \mathrm{e} 9$ & 0.30 & $4.0 \mathrm{e} 6$ & 1800 & 8 \\
7 & 3rd coal & $4 \mathrm{e} 9$ & 0.38 & $2.0 \mathrm{e} 6$ & 1500 & 2 \\
8 & aleurolite & $20 \mathrm{e} 9$ & 0.22 & $6.0 \mathrm{e} 6$ & 2000 & 3 \\
9 & 4th coal & $4 \mathrm{e} 9$ & 0.38 & $2.0 \mathrm{e} 6$ & 1600 & 2 \\
10 & mudstone & $8 \mathrm{e} 9$ & 0.32 & $2.5 \mathrm{e} 6$ & 1600 & 5 \\
11 & aleurolite & $20 \mathrm{e} 9$ & 0.22 & $6.0 \mathrm{e} 6$ & 2000 & 10 \\
\hline
\end{tabular}

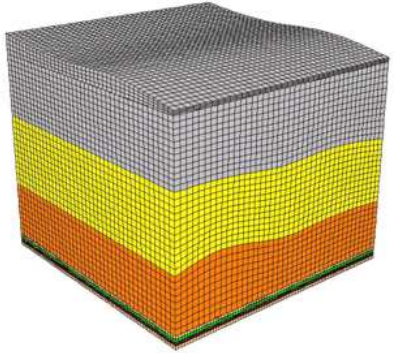

(a) Model without geological structure

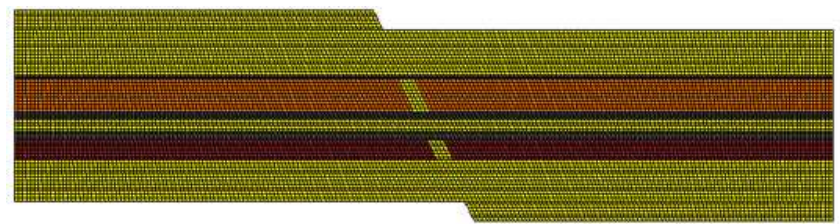

(b) Fault model

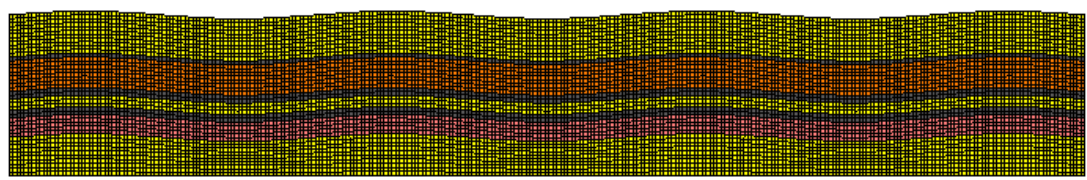

(c) Fold model

Fig. 1 Models

\section{Stress Field Inversion in No Geological Structure Area}

Just consider the gravity, which set as $9.8 \mathrm{~m} / \mathrm{s}^{2}$. After initial balance, find the corresponding zones according to coordinates of each measured point, then replace the zone data with measured value and recalculate. Table 3 shows the error between measured data and simulated result before and after adjustment. 
The adjustment above only affects the zones nearby, and the effect is poorer to the zones far distance. Therefore, stress regression analysis method [6] is used to fit the regional stress field without structures. Seven groups of stress data are needed, which include the four measured points shown in table 1 and the remains are chosen from simulation results. 1stOpt software solves the stress function and the result is listed in table 4.

Table 3 Error between measured data and simulated result before and after adjustment

\begin{tabular}{cccccccc}
\hline & No. of Measured Points & S-XX & S-YY & S-ZZ & S-XY & S-XZ & S-YZ \\
\hline \multirow{3}{*}{ Before } & D1 & $8.82 \%$ & $11.11 \%$ & $3.59 \%$ & $31.82 \%$ & $10.94 \%$ & $3.74 \%$ \\
adjustment & D2 & $12.20 \%$ & $7.26 \%$ & $5.62 \%$ & $13.22 \%$ & $10.48 \%$ & $9.13 \%$ \\
& D3 & $1.18 \%$ & $2.86 \%$ & $1.59 \%$ & $12.90 \%$ & $11.11 \%$ & $13.82 \%$ \\
& D4 & $21.84 \%$ & $17.39 \%$ & $10.14 \%$ & $57.06 \%$ & $11.89 \%$ & $12.67 \%$ \\
\hline \multirow{3}{*}{ After } & D1 & $2.45 \%$ & $3.03 \%$ & $0.96 \%$ & $20.13 \%$ & $4.06 \%$ & $1.12 \%$ \\
adjustment & D2 & $3.54 \%$ & $2.56 \%$ & $1.41 \%$ & $5.95 \%$ & $7.62 \%$ & $1.99 \%$ \\
& D3 & $0.59 \%$ & $1.14 \%$ & $0.40 \%$ & $20.89 \%$ & $24.87 \%$ & $3.27 \%$ \\
& D4 & $7.13 \%$ & $6.30 \%$ & $2.80 \%$ & $4.31 \%$ & $16.78 \%$ & $3.00 \%$ \\
\hline
\end{tabular}

Table 4 The regression coefficients of stress components

\begin{tabular}{ccccccc}
\hline 161.8 & -0.0039 & -0.3870 & -0.4218 & 0.0011 & $-4.75 \mathrm{e}-5$ & $-2.62 \mathrm{e}-6$ \\
122.5 & -0.0035 & -0.2935 & 0.3191 & 0.0008 & $-3.43 \mathrm{e}-5$ & $-1.78 \mathrm{e}-6$ \\
762.7 & -0.0182 & -1.8022 & -1.9992 & 0.0050 & -0.0003 & $-1.23 \mathrm{e}-5$ \\
0.3206 & $-1.58 \mathrm{e}-6$ & -0.0008 & -0.0008 & $2.10 \mathrm{e}-6$ & 0 & 0 \\
4.3097 & $2.67 \mathrm{e}-5$ & -0.0102 & -0.0114 & $2.84 \mathrm{e}-5$ & $-1.44 \mathrm{e}-6$ & 0 \\
-7.8102 & $4.24 \mathrm{e}-5$ & 0.0184 & 0.0205 & $-5.17 \mathrm{e}-5$ & $2.83 \mathrm{e}-6$ & 0 \\
\hline
\end{tabular}

So the regional stress function can be expressed as follows:

$\left.\begin{array}{l}\sigma \mathrm{x}=161.8-0.0039 \mathrm{~h}-0.387 \mathrm{x}-0.4218 \mathrm{y}+0.0011 \mathrm{xy}-4.75 \mathrm{e}-5 \mathrm{x}^{2}-2.62 \mathrm{e}-6 \mathrm{y}^{2} \\ \sigma \mathrm{y}=122.5-0.0035 \mathrm{~h}-0.2935 \mathrm{x}+0.3191 \mathrm{y}+0.0008 \mathrm{xy}-3.43 \mathrm{e}-5 \mathrm{x}^{2}-1.78 \mathrm{e}-6 \mathrm{y}^{2} \\ \sigma \mathrm{z}=762.7-0.0182 \mathrm{~h}-1.8022 \mathrm{x}-1.9992 \mathrm{y}+0.005 \mathrm{xy}-0.0003 \mathrm{x}^{2}-1.23 \mathrm{e}-5 \mathrm{y}^{2} \\ \tau \mathrm{xy}=0.3206-1.58 \mathrm{e}-6 \mathrm{~h}-0.0008 \mathrm{x}-0.0008 \mathrm{y}+2.1 \mathrm{e}-6 \mathrm{xy} \\ \tau \mathrm{xz}=4.3097+2.67 \mathrm{e}-5 \mathrm{~h}-0.0102 \mathrm{x}-0.0114 \mathrm{y}+2.84 \mathrm{e}-5 \mathrm{xy}-1.44 \mathrm{e}-6 \mathrm{x}^{2} \\ \tau \mathrm{yz}=-7.8102+4.24 \mathrm{e}-5 \mathrm{~h}+0.0184 \mathrm{x}+0.0205 \mathrm{y}-5.17 \mathrm{e}-5 \mathrm{xy}+2.83 \mathrm{e}-6 \mathrm{x}^{2}\end{array}\right\}$

The letters $x, y$ and $h$ in formula (1) stand for the coordinates and depth respectively. Stress components of each point in 3rd coal seam roof will be easily got according to formula (1).

\section{Numerical Simulation of Stress Field near the Fault}

The load on upper surface sets as $13 \mathrm{MPa}$. Fault plane is considered as interface and parameters of the range within two meters on both sides of the face is cut down by $1 / 2$. Boundary conditions is set according to the fault formation mechanism and calculation step is used to control fault gap.

This paper used Surfer8.0 to analyze the simulation results. Figure 2 is stress isoline and stress vector vertical projection of normal fault F1 model. Figure 3 shows the stress variation curve of 3 rd coal seam roof near fault F1. Fault F2 and F3 are the similar.
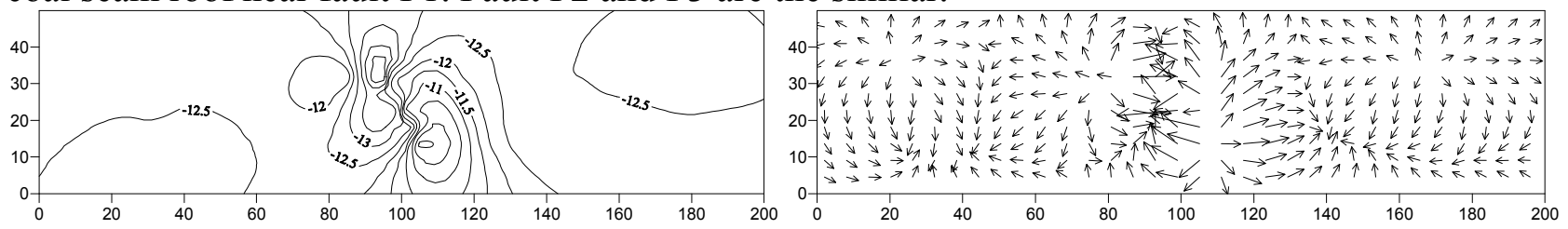

(a) The maximum principal stress /Mpa
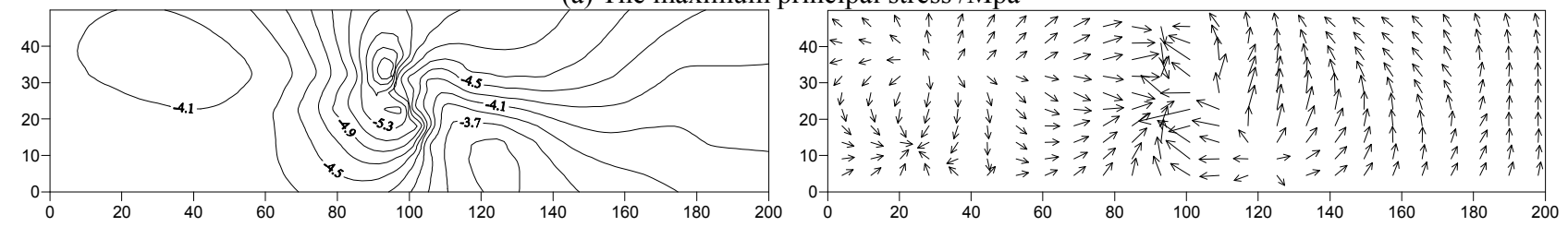

(b) The middle principal stress /Mpa 

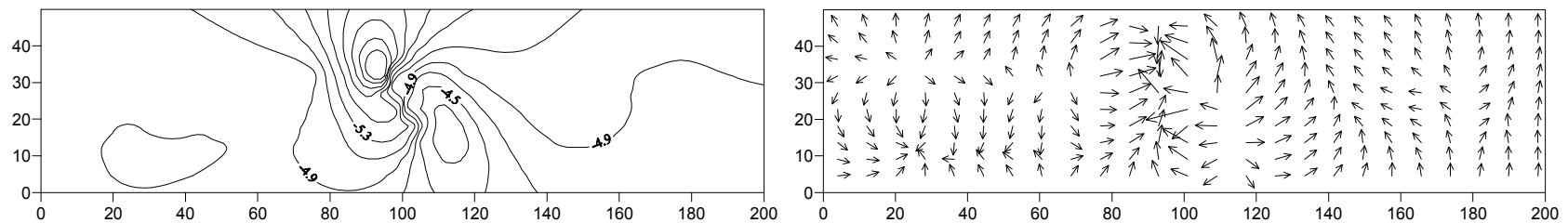

(c) The minimum principal stress /Mpa

Fig. 2 Stress isoline (left) and stress vector vertical projection (right) near fault F1

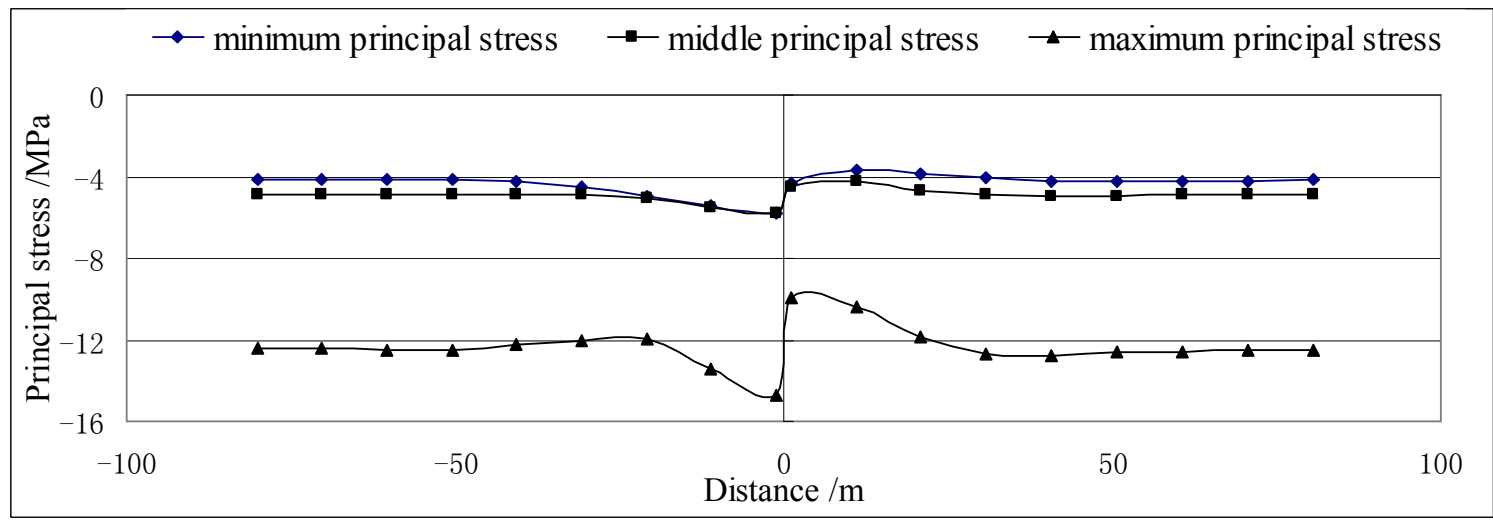

Fig. 3 Principal stress variation curve of coal seam roof near fault F1

Influence range and coefficients can be determined from figure 3, the coefficient is defined as the ratio of each point's stress value within the influence range and out the influence range. Influence coefficient of the three faults is listed in table 5.

Table 5 Stress adjustment coefficients near fault structure

\begin{tabular}{|c|c|c|c|c|c|c|c|c|c|c|c|}
\hline \multirow{2}{*}{ Distance /m } & \multicolumn{3}{|c|}{ F1 } & \multirow{2}{*}{ Distance $/ \mathrm{m}$} & \multicolumn{3}{|c|}{$\mathrm{F} 2$} & \multirow{2}{*}{ Distance /m } & \multicolumn{3}{|c|}{ F3 } \\
\hline & $\mathrm{S}_{\min }$ & $\mathrm{S}_{\mathrm{mid}}$ & $S_{\max }$ & & $\mathrm{S}_{\min }$ & $\mathrm{S}_{\mathrm{mid}}$ & $\mathrm{S}_{\max }$ & & $\mathrm{S}_{\min }$ & $\mathrm{S}_{\mathrm{mid}}$ & $S_{\max }$ \\
\hline-41 & 1.01 & 1.01 & 0.98 & -39 & 1.01 & 1.07 & 0.99 & -41 & 0.97 & 0.99 & 0.99 \\
\hline-31 & 1.08 & 1.02 & 0.96 & -29 & 1.05 & 1.14 & 1.00 & -31 & 1.01 & 0.95 & 0.91 \\
\hline-21 & 1.18 & 1.04 & 0.96 & -19 & 1.12 & 1.29 & 1.02 & -21 & 1.03 & 0.91 & 0.89 \\
\hline-11 & 1.30 & 1.14 & 1.08 & -9 & 1.18 & 1.51 & 1.05 & -12 & 1.08 & 0.92 & 0.91 \\
\hline-1 & 1.39 & 1.20 & 1.17 & -1 & 1.28 & 1.30 & 1.20 & -2 & 1.34 & 1.23 & 1.06 \\
\hline 1 & 1.04 & 0.92 & 0.79 & 1 & 0.98 & 0.80 & 1.11 & 0 & 1.15 & 1.08 & 1.11 \\
\hline 11 & 0.89 & 0.86 & 0.83 & 9 & 1.01 & 1.10 & 0.97 & 10 & 0.78 & 0.81 & 1.14 \\
\hline 21 & 0.93 & 0.92 & 0.95 & 19 & 1.02 & 1.07 & 1.01 & 20 & 0.75 & 0.81 & 1.00 \\
\hline 31 & 0.97 & 0.96 & 1.01 & 29 & 0.99 & 1.02 & 0.99 & 30 & 0.84 & 0.92 & 0.92 \\
\hline 41 & 0.98 & 0.99 & 1.02 & 39 & 0.98 & 1.02 & 0.98 & 39 & 0.98 & 0.91 & 0.86 \\
\hline
\end{tabular}

\section{The Influence of Fold Structure on Stress Field}

The load on upper surface sets as 13Mpa too. Displacement rate is set on both left and right boundary to shorten the rock seam in horizontal direction so that the seam will be bent and become fold. Calculation step is used to control extent. Displacement rate is set as $0.005 \mathrm{~m} / \mathrm{step}$ to first $6000 \mathrm{steps}$, then $0.0005 \mathrm{~m} / \mathrm{step}$ to next 10000 steps, and $0.0001 \mathrm{~m} / \mathrm{step}$ to the last 10000 steps. Figure 4 is stress isoline and stress vector vertical projection of fold $\mathrm{Z} 1$ model. Figure 5 shows the stress variation curve of 3rd coal seam roof near fold Z1.
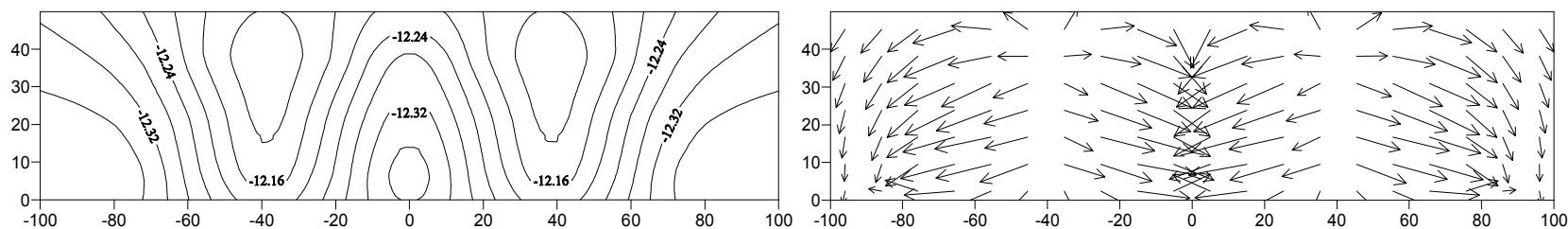

(a) The maximum principal stress $/ \mathrm{Mpa}$ 

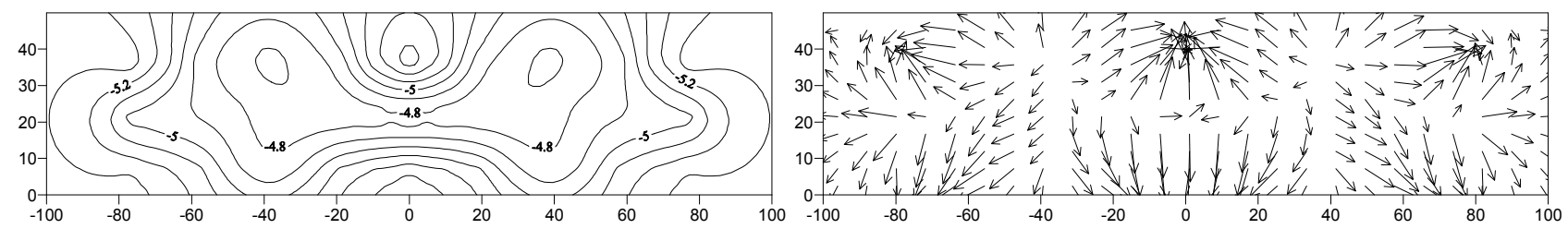

(b) The middle principal stress $/ \mathrm{Mpa}$
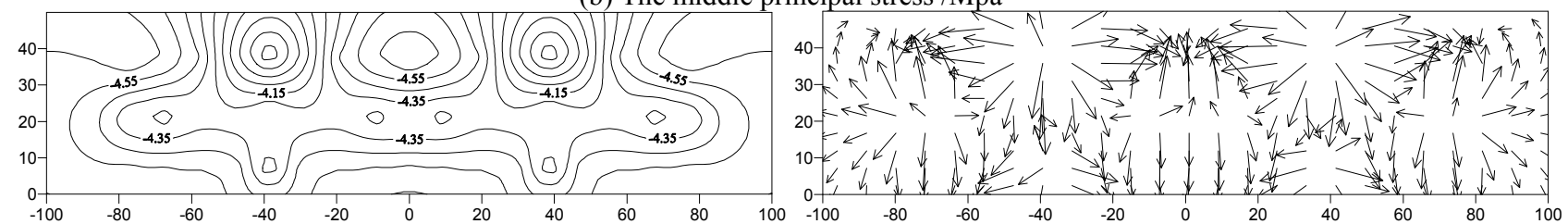

(c) The minimum principal stress /Mpa

Fig. 4 Stress isoline (left) and stress vector vertical projection (right) near fold Z1

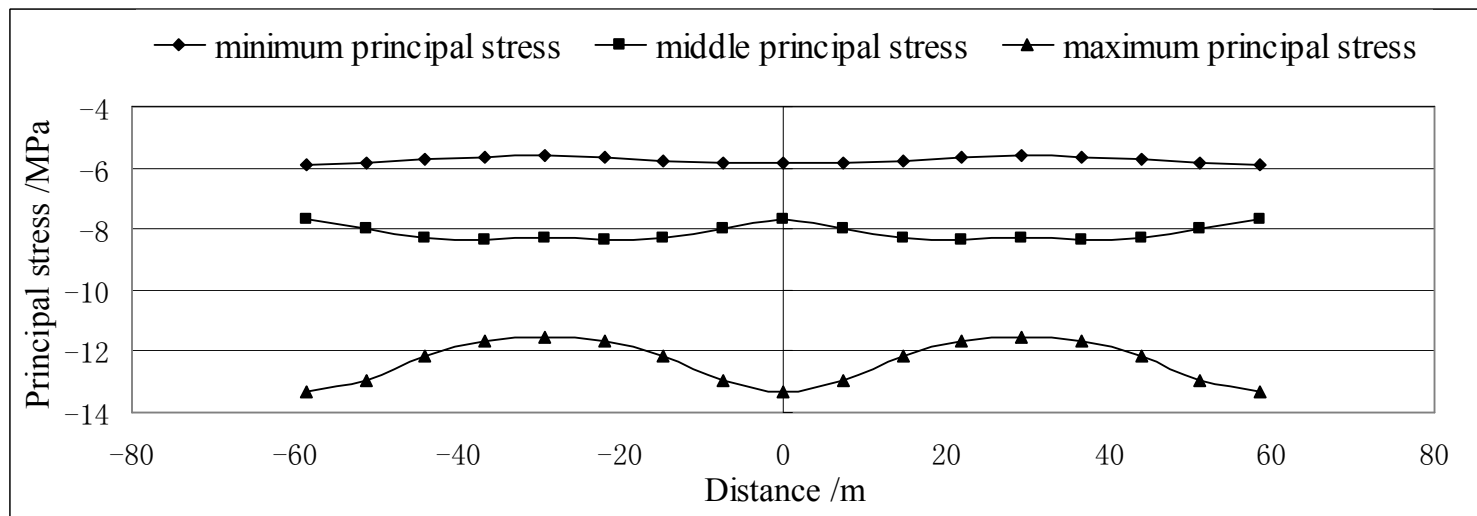

Fig. 5 The stress variation curve of coal seam roof near fold Z1

Influence coefficient of fold $\mathrm{Z} 1$ is listed in table 6.

Table 6 Stress adjustment coefficients near fold structure

\begin{tabular}{|c|c|c|c|c|c|c|c|c|c|c|c|c|}
\hline Dist & ce $/ \mathrm{m}$ & -59 & -44 & -29 & -22 & -7 & 0 & 7 & 22 & 37 & 44 & 59 \\
\hline \multirow{3}{*}{ Z1 } & $\mathrm{S}_{\min }$ & 1.43 & 1.4 & 1.36 & 1.38 & 1.42 & 1.42 & 1.42 & 1.38 & 1.37 & 1.4 & 1.43 \\
\hline & $\mathrm{S}_{\mathrm{mid}}$ & 1.57 & 1.7 & 1.69 & 1.7 & 1.63 & 1.57 & 1.63 & 1.7 & 1.7 & 1.7 & 1.57 \\
\hline & $\mathrm{S}_{\max }$ & 1.06 & 0.97 & 0.91 & 0.93 & 1.03 & 1.06 & 1.03 & 0.93 & 0.93 & 0.97 & 1.06 \\
\hline
\end{tabular}

\section{Analysis of Stress in Coal Seam Roof in Tectonic Area}

Stress field of no tectonic area on 3rd coal seam roof contour map is adjusted according to the local stress influence coefficients and Surfer8.0 software is used to draw principal stress isoline.

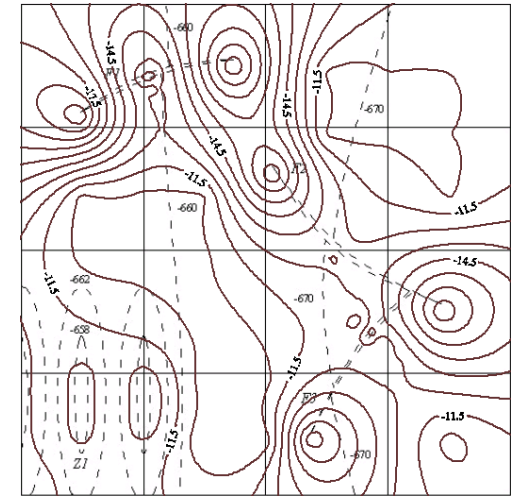

(a) The maximum principal stress /Mpa

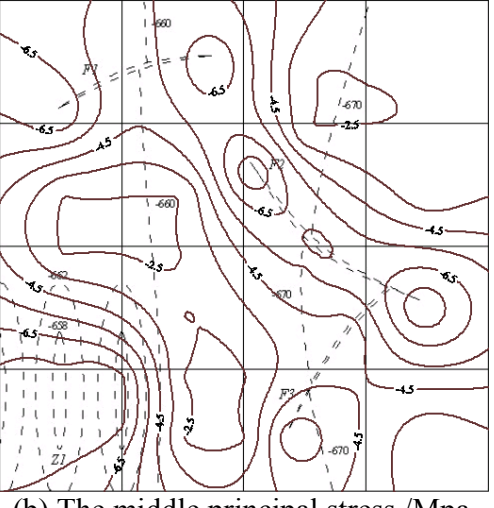

(b) The middle principal stress /Mpa

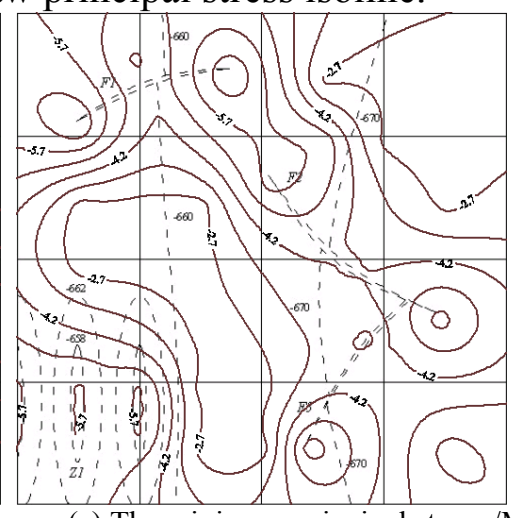

(c) The minimum principal stress /Mpa

Fig. 6 The principal stress isoline

First, find each adjustment point's corresponding point from big model, then stress value is multiplied by the influence coefficient shown in table 4 and table 5. After drawn by Surfer8.0 software, the stress isoline of $3 \mathrm{rd}$ coal seam roof is added to $3 \mathrm{rd}$ coal seam roof contour map (the dotted line shown in figure 6), and gained the complete principal stress isoline shown in Figure 6. 
Figure 7 is the isoline of angle between principal stress and vertical direction, from which we can get the conclusion that in area without geological structures, the maximum principal stress is roughly in the vertical direction, and the middle and minimum principal stress is mainly in horizontal condition, but in the tectonic area stress direction changes greatly with poor regularity.

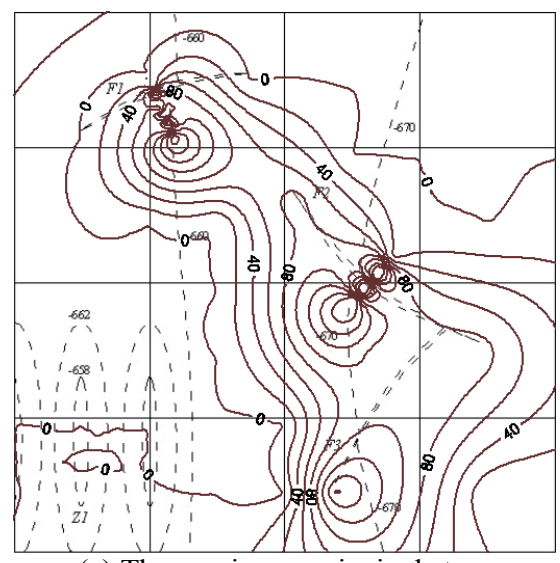

(a) The maximum principal stress

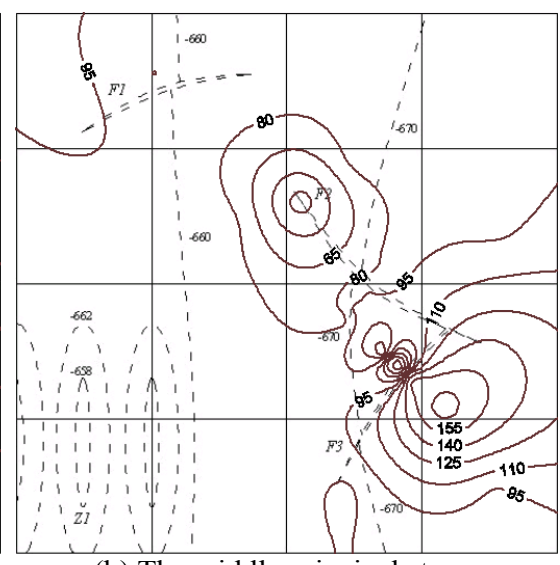

(b) The middle principal stress

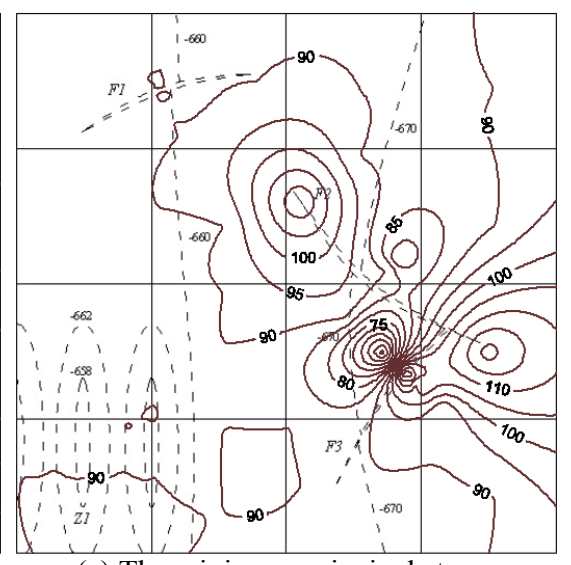

(c) The minimum principal stress

Fig. 7 The isoline of angle between principal stress and vertical direction

\section{Conclusions}

This paper took simulations respectively and integration together as the research thoughts. In a big model without geological structure, it corrected the simulation results according to measured data, and got the geostress field by regression analysis. In the small regional structure models, it gained the influence range and coefficients of each geological structure to the geostress field. At last, it integrated the results together, got the large area stress field under complex geological condition. The method is suitable for a large area which contains a lot of geological structures. When simulating the geological structures, it gives up the way of presetting structures but loads directly according to the formation mechanism of geological structures, which could better reflect the stress distribution rule near structures.

The deficiency in the paper, comparing simulation results with measured data in the area without structures, is that the normal stress fit well while shear stress has more errors, which is the bottleneck problem of the current inversion of initial geostress. In addition, when to a certain degree of extrusion in fold simulation, FLAC ${ }^{3 \mathrm{D}}$ program will stop operation because of individual zones' shape getting illegal, which is a topic that should be further studied in geostress simulation.

\section{Acknowledgements}

This work was financially supported by National Nature Science Foundation of China(51004068).

\section{References}

[1] Qihu Qian: Chinese Science \& Technology Press. 2000 (In Chinese)

[2] Yunfang Liu,etc: Hubei Science \& Technology Press. 2000 (In Chinese)

[3] Fengbo Yuan: Master's degree thesis of Chinese Academy of Sciences graduate school, 2003 (In Chinese)

[4] Yanxin Zhang, Meifeng Cai: Journal of University of Science and Technology Beijing. Vol.27(2005), p.520-523 (In Chinese)

[5] Bin Ma: Master's degree thesis of Tianjin university, 2003 (In Chinese)

[6] Yongsong Li, Jianmin Yin: Journal of Wuhan university(engineering science). Vol.40(2007), p.69-77 (In Chinese) 
Advances in Civil Engineering, ICCET 2011

10.4028/www.scientific.net/AMM.90-93

Numerical Simulation of Regional Stress Field under Complex Geological Condition

10.4028/www.scientific.net/AMM.90-93.531 